\title{
Exploration of in vitro thrombolytic, anthelminthic, cytotoxic and in vivo anxiolytic potentials with phytochemical screening of flowers of Brassica nigra
}

\author{
Mohammad Sarowar Uddin ${ }^{1 *}$ (D), Md. Shalahuddin Millat ${ }^{1}$, Mohammad Safiqul Islam', Md. Saddam Hussain ${ }^{1}$, \\ Md. Giash Uddin ${ }^{2}$, Shafayet Ahmed Siddiqui ${ }^{3}$ and Mahmuda Ferdous ${ }^{1}$
}

\begin{abstract}
Background: Brassica nigra is a plant of Brassicaceae family, which possesses numerous medicinal values. Our present study is intended to assess the potential in vitro thrombolytic, anthelminthic, cytotoxic and in vivo anxiolytic properties of MCE of B. nigra flowers. MCE was fractioned for separating the compound on the basis of polarity by using chloroform, $n$-hexane and ethyl acetate solvent. Thrombolytic and anthelminthic activities were explained by collecting human erythrocytes and earthworms as test models, respectively. Anxiolytic activity was evaluated by elevated plus maze and hole board models while cytotoxic test was conducted through brine shrimp lethality bioassay.

Results: MCE revealed the presence of alkaloids, flavonoids, tannin, diterpenes, glycosides, carbohydrates, phenols, fixed oils and fat. In case of thrombolytic test, the MCE, CSF, ASF and n-HSF had produced maximum clot lysis activity at 5 and $10 \mathrm{mg} / \mathrm{ml}$ dose conditions. Two different concentrations (10 and $20 \mathrm{mg} / \mathrm{ml}$ ) of MCE and its fractions showed significant $(p<0.05)$ anthelminthic activities in a dose-dependent manner. Significant anxiolytic activity was observed for all fractions which was comparable to the standard drug diazepam $(p<0.05)$. Again, the cytotoxic screening also presented good potentials for all fractions.

Conclusion: From the findings of present study, we can conclude that MCE of B. nigra flowers and its fraction possess significant anxiolytic, anthelmintic, anticancer and thrombolytic properties which may be a good candidate for treating these diseases through the determination of bio-active lead compounds.
\end{abstract}

Keywords: Brassica nigra, Anxiolytic, Anthelmintic, Thrombolytic, Cytotoxic activity

\section{Background}

Various types of plants have been used in conventional medicine throughout the world for thousands of years, and they are providing new medications for today [1]. It has been stated that about $64 \%$ of world population is using conventional medicine to meet their healthcare needs [2]. A number of current medications used in the

\footnotetext{
* Correspondence: pharmasarowar@gmail.com

${ }^{1}$ Department of Pharmacy, Noakhali Science \& Technology University,

Noakhali 3814, Bangladesh

Full list of author information is available at the end of the article
}

treatment of various chronic and severe conditions have been originated from plants which were discovered by the human being in the course of time [3]. Such type of conventional medicines is used in both developed and developing countries for primary healthcare due to their wide biological and medicinal activities, higher safety and low prices [3]. By this way, allopathic medicine has replaced by medicines from natural sources for the treatment of many diseases in recent times that show considerable therapeutic activity [4]. Plants are also providing the raw materials for the treatment of various life-

\section{Springer Open}

(0) The Author(s). 2020 Open Access This article is licensed under a Creative Commons Attribution 4.0 International License, which permits use, sharing, adaptation, distribution and reproduction in any medium or format, as long as you give appropriate credit to the original author(s) and the source, provide a link to the Creative Commons licence, and indicate if changes were made. The images or other third party material in this article are included in the article's Creative Commons licence, unless indicated otherwise in a credit line to the material. If material is not included in the article's Creative Commons licence and your intended use is not permitted by statutory regulation or exceeds the permitted use, you will need to obtain permission directly from the copyright holder. To view a copy of this licence, visit http://creativecommons.org/licenses/by/4.0/. 
threatening disorders [5]. This information encouraged us to search for new plants in order to disclosing different pharmacological activities.

Human beings are suffering from various diseases. Among these diseases, thromboembolic disorders such as pulmonary emboli, deep vein thrombosis, strokes and heart attacks are the main causes of morbidity and mortality in both developing and developed countries [6]. Various thrombolytic agents such as alteplase, streptokinase, urokinase and tissue plasminogen activator (TPA) are widely used to dissolve clots [6]. These drugs have some limitations which cause severe and sometimes fatal disorders including haemorrhage, severe anaphylactic reaction and lacked specificity [2]. That is why efforts have been focused towards the findings of natural products from various plant sources which belong to antiplatelet, anticoagulant, antithrombotic and thrombolytic activities. Again, anxiety disorders are the most prominent problems among many psychiatric disorders and approximately $10-30 \%$ of the general population are suffering from this globally [7]. It is a psychiatric disorder that causes significant impairment of personal functioning [7]. Benzodiazepines are the mostly prescribed synthetic drugs for anxiolytic, muscle relaxant, sedative-hypnotic and anticonvulsant actions [8]. These drugs cause impairment in cognitive functions, physical dependence and harmful effects on respiratory, digestive and immune systems of the body [9]. For this reason, the search of new anxiolytic and antidepressant agents with less adverse effects is still an area of great interest to the researchers [7].

Helminth infection, a parasitic disease, is thought to be caused by various parasitic worms such as flukes (Trematodes), roundworms (Nematodes) and tapeworms (Cestodes) [10]. It is highly seen in developing countries including Bangladesh owing to the lack of management and insufficient control measures [11, 12]. Again, cancer is another leading disease in which abnormal cellular growth, lack of control of the cell proliferation, differentiation and death usually occur [13]. There are various ways to address cancer such as surgery, radiation therapy and chemotherapy which aim to eradicate all cancerous cells from the body, but each of the treatment strategy has several limitations like drug resistance, toxicity and low specificity [14]. The synthetic chemotherapeutics which have currently been used possess several limitations, and thus, the initiation of novel chemotherapeutic agents from plant origin is increasing in recent years [15].

Human beings are greatly depending on nature from the very ancient times for their any primary health complaints, and nature is a good source of medicine which can be obtained from various types of plants [2]. Brassica nigra is such type of plant with a great medicinal value. Brassicaceae family plants are thought to be native to the eastern Mediterranean or the surrounding area, but nowadays, it has been grown all over Europe [16]. It is also grown in Bangladesh. It has been cultivated for millennia for fulfilling the demand of spice and is also considered as one of the most important ingredients in mustard industries [16]. B. nigra is non-mycorrhizal, and the presence of it decreases the soil biodiversity [17]. Brassica vegetables are greatly enriched with several nutritional values such as vitamin $C$ and nutrients with anticancer properties including 3-3-diindolylmethane, sulforaphane and selenium [18]. According to Kiasalari et al, the seeds of Brassica nigra posseses essential oils (omega-3 fatty acids), the minerals (selenium, phosphorus, magnesium,manganese, iron, zinc and calcium), vitamins (A, C and B-complex), protein (dietry fibre) and phytonutrients [19]. The phytochemical screening of seeds of Brassica nigra showed the presence of alkaloid, flavonoid, carbohydrate, fixed oil and glycosides [20]. It also showed the significant growth inhibitory activities against HeLa, HepG2, HCT, HEp2 and MCF-7 tumour cells [21]. Brassica vegetables contain indole-3-carbinol which inhibits the growth of cancer cell [22]. The seeds of Brassica are traditionally used in the treatment of cardiovascular diseases, neurotic pain, rheumatoid arthritis, brain and lung edema, paralysis, migraine, diabetes and its complications [19, 23]. It also belongs to antiepileptic and anxiolytic activity [20]. Furthermore, the leaves of $B$. nigra contain 3-3-diindolylmethane that is a potent modulator of the innate immune response system with potent antibacterial, antiviral and anticancer activity [24].

Considering the biomedical importance of $B$. nigra, we became interested to learn about the thrombolytic, anthelmintic, cytotoxic and anxiolytic activities of the flowers of $B$. nigra which is not still investigated. For this purpose, the study has been conducted.

\section{Methods \\ Collection of plant materials}

The flower of B. nigra (Brassicaceae) has been selected for the present study. For this investigation, B. nigra was collected from the local area of Noakhali, Bangladesh, in the month of March 2019 and was identified in Bangladesh National Herbarium (BNH), Dhaka, Bangladesh. A voucher specimen (DACB Accession No 45837) of the plant has been deposited in the herbarium.

\section{Preparation of plant extract}

The dried and powdered flowers $(500 \mathrm{~g})$ were soaked in $1500 \mathrm{ml}$ of $99 \%$ methanol for about 21 days at room temperature with occasional stirring. After 21 days, the solution was filtered using filter cloth and Whatman filter paper. A rotary evaporator was used under reduced pressure at $40{ }^{\circ} \mathrm{C}$ to obtain the concentrated methanol extract. 


\section{Solvent-solvent partitioning}

The residue (40 g) derived from methanol extract was subjected to vacuum liquid chromatography using nhexane, chloroform, ethyl acetate and water in order to increase polarity. The solvent-solvent partition of crude extract was performed according to Hossain et al. [14].

\section{Experimental animal}

For continuing the present experimentation, Swiss albino mice (both male and female) weighed between 20 and $25 \mathrm{~g}$ were used. These mice were collected from Jahangirnagar University, Dhaka, Bangladesh. Before the current research work, these animals were adjusted to standard animal house condition for 4 days [25]. Feeding of the animal was performed using standard laboratory pellet and water ad libitum, subjecting them to an alternate cycle of $12 \mathrm{~h}$ dark and light at relative humidity 55 $\pm 10 \%$ and temperature $25 \pm 2$ [25]. 'Principles of Laboratory Animal Care' (NIH publication no. 85-23, revised 1985) as well as specific national laws was followed by all authors.

\section{Drugs and chemicals}

Standard diazepam, dimethyl sulfoxide, vincristine sulphate (VS), albendazole and streptokinase were purchased from Square Pharmaceutical Ltd., Bangladesh. Other reagents of analytical grade for conducting this research work were supplied by the ethno pharmacology laboratory of the Pharmacy Department of NSTU.

\section{Phytochemical evaluation}

In order to determine the chemical groups present in the MCE, the preliminary phytochemical studies were conducted [26-28]. In each test, 10\% (w/v) solution of extract in methanol was taken for the detection of presence of chemical groups.

\section{Cytotoxicity by brine shrimp lethality bioassay}

In brine shrimp lethality bioassay, dimethyl sulfoxide (DMSO) was used as both solvent and negative control whereas vincristine sulphate (VS) was applied as the positive control [14]. DMSO solutions of the test samples were subjected to Artemia salina for a day in order to determine in vivo cytotoxic screening. Four milligrams of the each sample was dissolved in DMSO, and solutions of different concentrations (400, 200, 100, 50, $25,12.50,6.25,3.125,1.563,0.781 \mu \mathrm{g} / \mathrm{ml})$ were attained by serial dilution technique. Then, mature shrimps (10 pieces) were kept in each of the experimental vials. The vials were observed after $24 \mathrm{~h}$ using a magnifying glass, and the number of subsisting nauplii in each vial was determined. Using these data, the percentage (\%) of lethality of brine shrimp nauplii was calculated for each concentration by applying the following formula:

$$
\% \text { of mortality }=\frac{N t}{N o} \times 100
$$

Here, $N_{t}=$ the number of dead nauplii after $24 \mathrm{~h}$ of incubation and $N_{\mathrm{o}}=$ the number of total nauplii transferred (10)

Then, the median lethal concentration $\left(\mathrm{LC}_{50}\right)$ was calculated from the log concentration versus percentage of mortality curve.

\section{Anthelmintic assay}

To study the anthelmintic activity, adult earthworms were used [10, 29]. The earthworms (Pheretima posthuma) were collected from moist soil of NSTU campus and washed with normal saline to eradicate all the soil. The earthworms $4-6 \mathrm{~cm}$ in length and $0.1-0.3 \mathrm{~cm}$ in width weighing $0.8-4.04 \mathrm{~g}$ were used for all experiment protocols. Both anatomically and physiologically, the earthworms were assimilated with the intestinal worm parasites of human beings, and for this reason, it was used to study the anthelmintic activity. Albendazole was treated as the reference standard.

\section{Thrombolytic activity}

The thrombolytic activity of B. nigra was conducted according to the method described by Prasad et al. and Islam et al. [10, 30]. Five milliliters of venous blood was taken from healthy volunteers $(n=5)$ and transferred to different pre-weighed sterilised micro-centrifuge tube (1 $\mathrm{ml} /$ tube). The micro-centrifuge tubes were subjected to incubation at $37^{\circ} \mathrm{C}$. After $45 \mathrm{~min}$, the formation of clot occurred and serum was completely separated from the tubes (carried out without disturbing the clot formed) and the remaining clot of each tube was again weighed to calculate the weight of the clot [clot weight $(W 3)=$ weight of clot containing tube (W2) - weight of tube alone (W1)]. Each micro-centrifuge tube was labelled appropriately, and MCE and fractions with concentrations of 5 and $10 \mathrm{mg} / \mathrm{ml}$ were added to the tubes accordingly. One hundred microliters of streptokinase was used as a positive control whereas $100 \mu \mathrm{l}$ of sterilised distilled water was distinctly added to the control tubes numbered as a negative non-thrombolytic control. After that, the tubes were incubated again at $37{ }^{\circ} \mathrm{C}$ for $90 \mathrm{~min}$ for observing clot lysis. Then, following the incubation, the obtained fluid was removed from the tubes and these fluids were again weighed to observe the difference in weight after clot disruption. Finally, difference obtained in weight was determined and the result was expressed as the percentage of clot lysis using the following equation: 


$$
\% \text { of clot lysis }=\frac{W 3-W 4}{\text { weight of clot }} \times 100
$$

Here, $W 3=$ to weight $(\mathrm{g})$ of clot after $45 \mathrm{~min}$ incubation and $W 4=$ the weight $(\mathrm{g})$ of lysis clot after $90 \mathrm{~min}$ incubation.

\section{Evaluation of anxiolytic activity Elevated plus maze test}

To evaluate the anxiolytic activity, the elevated plus maze was constructed according to the description given by the researchers $[10,31]$. The EPM apparatus consists of two open arms $\left(35 \times 5 \mathrm{~cm}^{2}\right)$ elapsed by two closed arms $\left(35 \times 5 \times 15 \mathrm{~cm}^{3}\right)$. The two arms were attached at one place with a central square of $5 \times 5 \mathrm{~cm}^{2}$. The apparatus was placed in a dimly enlightened room. The Swiss albino mice (20-25 g) were kept fast for overnight and split into seven groups; each group consists of 5 animals. Distilled water $10 \mathrm{ml} / \mathrm{kg}$, i.p (negative control group); diazepam $1 \mathrm{mg} / \mathrm{kg}$, i.p (positive control group); and plant extracts 200 and $400 \mathrm{mg} / \mathrm{kg}$, i.p were administered to the individual groups of mice before the $60 \mathrm{~min}$ of test. The time spent and the number of entry in both open and close arms were recorded for $5 \mathrm{~min}$ [31].

\section{Hole board test}

The hole board apparatus used for anxiolytic test consists of 16 holes with a wooden chamber $(40 \times 40 \times 25$ $\mathrm{cm}^{3}$ ), and the diameter of each hole is $3 \mathrm{~cm}$. The apparatus was raised to the height of $25 \mathrm{~cm}$ from the floor so that the mice could peep through the holes. The Swiss albino mice (20-25 g) were divided into the control, standard and test groups. The control group received distilled water $10 \mathrm{ml} / \mathrm{kg}$, i.p and the standard group received diazepam $1 \mathrm{mg} / \mathrm{kg}$, i.p while the test group received extract 200 and $400 \mathrm{mg} / \mathrm{kg}$, i.p before the $60 \mathrm{~min}$ of test. Each mouse was kept at one corner of the board where the mouse could move freely and dip its head into the holes. The number of head dipping was recorded for 5 min [10, 32].

\section{Acute toxicity test}

Acute toxicity test was conducted according to Gandhare et al. [33]. The MCE of flowers of Brassica nigra was applied separately in various doses $(50,500,1000$, $2000 \mathrm{mg} / \mathrm{kg}$ ) in four groups of animals by oral route. The animals were observed continuously for the first $2 \mathrm{~h}$ and $24 \mathrm{~h}$ to identify the behavioural changes. However, there are no noticeable behavioural changes and mortality occurred. Therefore, we considered the extract be safe at a dose level $2000 \mathrm{mg} / \mathrm{kg}$ and $\mathrm{LD}_{50}$ be $>2000 \mathrm{mg} /$ $\mathrm{kg}$.

\section{Statistical analysis}

The data obtained in the studies were subjected to oneway analysis of variance (ANOVA) for determining the significant differences. The intergroup significance was analysed by using Dunnett's $t$ test. " $p<0.05,{ }^{* * *} p<0.01$ and ${ }^{* * *} p<0.001$ indicate weak, moderate and high significance, respectively. All the values were expressed as mean $\pm \operatorname{SEM}(n=5)$.

\section{Results}

\section{Phytochemical screening}

The phytochemical screening of MCE of $B$. nigra showed the presence of alkaloids, flavonoids, saponin, tannin, diterpenes, glycosides, carbohydrates, phenols fixed oils and fat which is exhibited in Table 1. Based on these results, the MCE of $B$. nigra was subjected to pharmacological investigations such as cytotoxic activity, anthelmintic activity, anxiolytic activity and thrombolytic activity. The study showed that the plant can be used for various purposes.

\section{Cytotoxic investigation}

The results of the toxicity of the MCE, CSF, ASF, EASF and $\mathrm{n}$-HSF against brine shrimp ( $\mathrm{LC}_{50}$ values) are shown in Table 2. By using the process developed by Meyer, we determined $\mathrm{LC}_{50}$ (lethal concentration, $50 \%$ ) of $\mathrm{MCE}$ and its four fractions. From the results of the brine shrimp lethality bioassay, it is observed that the CSF demonstrated greater toxicity $(1.563 \mu \mathrm{g} / \mathrm{ml})$ compared with others and ASF exerted the lowest percentage of mortality. So it can nicely be predicted that the MCE and its fractions possess cytotoxic properties compared with positive control VS. However, no mortality was observed for the negative control group.

Table 1 Preliminary phytochemical analysis of $B$. nigra flowers

\begin{tabular}{ll}
\hline Phytochemicals & Comment \\
\hline Alkaloid & ++ \\
Saponin & + \\
Tannin & ++ \\
Flavanoids & ++ \\
Carbohydrate & ++ \\
Diterpenes & + \\
Protein & - \\
Phytosterols & + \\
Glycosides & + \\
Phenol & ++ \\
Fixed oils and fat & ++ \\
\hline
\end{tabular}

Here, ' + ' means present, ' ++ ' means strongly present and ' - ' means absent 
Table 2 Cytotoxic activity of vincristine sulphate (VS), MCE and its fractions on brine shrimp nauplii

\begin{tabular}{llll}
\hline Sample & $\mathbf{L C}_{\mathbf{5 0}}(\boldsymbol{\mu} \mathbf{g} / \mathbf{m l})$ & Regression equation & $\boldsymbol{R}^{\mathbf{2}}$ \\
\hline VS & 0.709 & $y=39.765 x+55.949$ & 0.96 \\
MCE & 5.586 & $y=30.709 x+27.058$ & 0.8848 \\
n-HSF & 3.019 & $y=25.912 x+37.516$ & 0.8028 \\
CSF & 1.563 & $y=22.029 x+45.724$ & 0.9454 \\
EASF & 3.730 & $y=17.37 x+40.069$ & 0.9291 \\
ASF & 10.168 & $y=21.394 x+28.451$ & 0.9739
\end{tabular}

VS vincristine sulphate, $M C E$ methanol crude extract, EASF ethyl acetate soluble fraction, $n$-HSF n-hexane soluble fraction, CSF chloroform soluble fraction, ASF aqueous soluble fraction

\section{Anthelmintic activity}

The result of anthelmintic activity is shown in Table 3. From the result, it was seen that all fractions cause the death and paralysis of Phertima posthuma in a dosedependent manner which is significant $(p<0.05)$ when compared with standard drug albendazole. Here, n-HSF at the concentration $10 \mathrm{mg} / \mathrm{ml}$ showed paralysis and death at $13.20 \pm .58 \mathrm{~min}$ and $22.40 \pm 1.36 \mathrm{~min}$, respectively. Again, time taken for paralysis and death was 8.80 $\pm .97 \mathrm{~min}$ and $15.60 \pm 1.08 \mathrm{~min}$, respectively, at a concentration of $20 \mathrm{mg} / \mathrm{ml}$ for n-HSF. Moreover, in case of albendazole $(20 \mathrm{mg} / \mathrm{ml})$, the paralysis time was $20.80 \pm$ $1.28 \mathrm{~min}$ whereas death time was $54.00 \pm 1.45 \mathrm{~min}$. Thus, other fractions also exhibited significant anthelmintic activity in a dose-dependent fashion. Here, n-HSF demonstrated higher anthelmintic activity against the earthworm.

\section{Anxiolytic activity}

In the EPM test, the MCE and its fractions at dose 200 and $400 \mathrm{mg} / \mathrm{kg}$ showed (Table 4) an increase of time spending in open arm in a dose-dependent manner which indicates the anxiolytic activity of the plant [10]. All the fractions exhibited good anxiolytic activity but $\mathrm{n}$ HSF showed relatively good activity as compared to standard. Times spent by mice in open and closed arm for $\mathrm{n}$-HSF at dose $200 \mathrm{mg} / \mathrm{kg}$ were $72.20 \pm 2.71 \mathrm{~s}$ and $192.80 \pm 2.35 \mathrm{~s}$ while it was $80.80 \pm 1.46 \mathrm{~s}$ and $183.00 \pm$ $2.43 \mathrm{~s}$ at dose $400 \mathrm{mg} / \mathrm{kg}$, respectively. On the other hand, time spent by mice in open and close arm for standard was $102.20 \pm 3.71 \mathrm{~s}$ and $170.00 \pm 3.49 \mathrm{~s}$, respectively. Again the number of entries in open arm was also increased with the increase of dose whereas it was decreased in case of close arm. In the hole board model, the number of head dipping was measured (Table 5). The result showed significant increase in head dipping counts with the increase of dose which is significant when compared with standard and indicates the presence of anxiolytic activity.

\section{Thrombolytic activity}

The MCE of $B$. nigra flowers was assessed for thrombolytic activity, and the results are presented in Table 6. The addition of $100 \mu \mathrm{l}$ streptokinase as a positive control showed $46.39 \%$ clot lysis. On the other hand, distilled water was treated as a negative control which exhibited a negligible percentage of lysis of clot (6\%). Among the different fractions, the highest percentage of clot lysis activity was $30.77 \pm$ $4.09 \%$ and $36.89 \pm 1.94 \%$ at the concentration of 5 and $10 \mathrm{mg} / \mathrm{ml}$, respectively, for CSF. Other fractions also exhibited potentiality of clot lysis at a dosedependent manner which was significant when compared with the negative control $(p<0.05)$.

Table 3 Time recorded for paralysis and death of earthworms for flowered extract of B. nigra and standard drug

\begin{tabular}{|c|c|c|c|}
\hline \multirow[t]{2}{*}{ Sample } & \multirow{2}{*}{$\begin{array}{l}\text { Concentration } \\
(\mathrm{mg} / \mathrm{ml})\end{array}$} & \multicolumn{2}{|l|}{ Time (min) } \\
\hline & & Paralysis time & Death time \\
\hline \multirow[t]{2}{*}{ Standard (albendazaole) } & 10 & $35.40 \pm 0.51$ & $73.40 \pm 1.21$ \\
\hline & 20 & $20.80 \pm 1.28$ & $54.00 \pm 1.45$ \\
\hline \multirow[t]{2}{*}{ CSF } & 10 & $17.80 \pm .58^{* * *}$ & $30.80 \pm 1.11^{* * *}$ \\
\hline & 20 & $11.80 \pm 1.02^{* *}$ & $22.00 \pm 1.00^{* * *}$ \\
\hline \multirow[t]{2}{*}{ ASF } & 10 & $87.60 \pm 0.51^{* * *}$ & $99.40 \pm 0.81^{* * *}$ \\
\hline & 20 & $54.40 \pm 1.29^{* * *}$ & $67.60 \pm 2.42^{* *}$ \\
\hline \multirow[t]{2}{*}{ MCE } & 10 & $53.60 \pm 0.81^{* * *}$ & $62.20 \pm 0.97^{* *}$ \\
\hline & 20 & $33.80 \pm 1.24^{* *}$ & $47.40 \pm 1.57^{* *}$ \\
\hline \multirow[t]{2}{*}{$n-\mathrm{HSF}$} & 10 & $13.20 \pm 0.58^{* * *}$ & $22.40 \pm 1.36^{* * *}$ \\
\hline & 20 & $8.80 \pm 0.97^{* *}$ & $15.60 \pm 1.08^{* * *}$ \\
\hline Control (1\% CMC in normal saline) & - & - & - \\
\hline
\end{tabular}

Each value represents the mean $\pm \operatorname{SEM}(n=5)$

MCE methanol crude extract, EASF ethyl acetate soluble fraction, $n$-HSF n-hexane soluble fraction, CSF chloroform soluble fraction, SEM standard error mean The inter group significance was analysed by one-way ANOVA using Dunnet's t-test. $P<0.05^{*}, P<0.01^{* *}$ and $P<0.001^{* * *}$ indicates weak, moderate and high significance respectively 
Table 4 Effects of MCE and its fractions of B. nigra flowers on mice in the open and closed arm of the EPM

\begin{tabular}{|c|c|c|c|c|c|}
\hline \multirow[t]{2}{*}{ Sample } & \multirow{2}{*}{$\begin{array}{l}\text { Doses } \\
(\mathrm{mg} / \\
\mathrm{kg})\end{array}$} & \multicolumn{2}{|c|}{ Time spent in seconds (mean \pm SEM) } & \multicolumn{2}{|c|}{ Number of entries (mean \pm SEM) } \\
\hline & & Open arm & Closed arm & Open arm & Closed arm \\
\hline Control & 10 & $19.40 \pm 2.64$ & $254.00 \pm 2.07$ & $7.00 \pm 0.71$ & $28.33 \pm 2.03$ \\
\hline Standard & 1 & $102.20 \pm 3.71$ & $170.00 \pm 3.49$ & $18.60 \pm 0.51$ & $7.33 \pm 1.45$ \\
\hline \multirow[t]{2}{*}{$\mathrm{n}-\mathrm{HSF}$} & 200 & $72.20 \pm 2.71^{* *}$ & $192.80 \pm 2.35^{* *}$ & $13.60 \pm 0.81^{* *}$ & $6.40 \pm 0.51^{* * *}$ \\
\hline & 400 & $80.80 \pm 1.46^{*}$ & $183.00 \pm 2.43$ & $14.80 \pm 0.80$ & $8.68 \pm 2.11^{* * *}$ \\
\hline \multirow[t]{2}{*}{ CSF } & 200 & $59.80 \pm 4.53^{* *}$ & $205.00 \pm 1.87^{* *}$ & $11.40 \pm 0.68^{* *}$ & $7.60 \pm 0.51^{* * *}$ \\
\hline & 400 & $72.60 \pm 2.01^{* *}$ & $195.40 \pm 1.75^{* *}$ & $13.00 \pm 0.71^{* *}$ & $9.62 \pm 0.61^{* * *}$ \\
\hline \multirow[t]{2}{*}{ EASF } & 200 & $43.20 \pm 1.43^{* *}$ & $230.60 \pm 1.75^{* * *}$ & $7.60 \pm 0.51^{* * *}$ & $10.60 \pm 0.51^{* * *}$ \\
\hline & 400 & $48.80 \pm 1.46^{* * *}$ & $224.20 \pm 1.88^{* * *}$ & $9.60 \pm 0.60^{* * *}$ & $12.43 \pm 0.60^{* * *}$ \\
\hline \multirow[t]{2}{*}{ MCE } & 200 & $59.20 \pm 0.97^{* *}$ & $210.20 \pm 1.85^{* *}$ & $10.60 \pm 0.51^{* *}$ & $11.40 \pm 0.68^{* * *}$ \\
\hline & 400 & $66.80 \pm 1.50^{* *}$ & $199.60 \pm 2.50^{* * *}$ & $12.40 \pm 0.60^{* *}$ & $13.12 \pm 0.71^{* *}$ \\
\hline \multirow[t]{2}{*}{ ASF } & 200 & $38.60 \pm 0.93^{* * *}$ & $234.80 \pm 2.42^{* * *}$ & $6.40 \pm 0.51^{* * *}$ & $13.60 \pm 0.81^{* *}$ \\
\hline & 400 & $44.00 \pm 2.10^{* * *}$ & $226.40 \pm 0.67^{* * *}$ & $8.60 \pm 2.10^{* * *}$ & $14.80 \pm 0.80^{*}$ \\
\hline
\end{tabular}

Each value represents the mean $\pm \operatorname{SEM}(n=5)$

MCE methanol crude extract, EASF ethyl acetate soluble fraction, $n$-HSF n-hexane soluble fraction, CSF chloroform soluble fraction, ASF aqueous soluble fraction, SEM standard error mean

The inter group significance was analysed by one-way ANOVA using Dunnet's t-test. $P<0.05^{*}, P<0.01^{* *}$ and $P<0.001^{* * *}$ indicates weak, moderate and high significance respectively

\section{Discussion}

Human beings are relying on plants for the treatment of many diseases from the very beginning of civilization [34]. At present, phyto-pharmacological study has opened a new area to discover plant derivative drugs which are effective for the treatment of certain diseases and draw the attention in herbal medicines [34]. About $30 \%$ of pharmaceuticals are thought to be prepared from plant derivatives [35].

A number of studies have been conducted to explore the safe and effective drugs in order to address the treatment of cancer or tumour. Here, we tried to find out any ingredient that may lie in MCE and may be effective in cancer or tumour through cytotoxic investigation. In this investigation, varying degree of lethality was found with exposure to different dose levels of the test samples. The degree of lethality was found, which is directly proportional to the concentration gradient which indicates that mortality increases gradually with the increase of concentration of the test samples. The MCE and its fractions exhibited (Table 1) significant toxicity to brine shrimp as the $\mathrm{LC}_{50}$ values were less than

Table 5 Effects of MCE and its fractions of B. nigra flowers on mice in hole board test

\begin{tabular}{lll}
\hline Sample & Doses $(\mathbf{m g} / \mathbf{k g})$ & Number of head dipping $(\mathbf{3 0 0} \mathbf{s}$ test) in hole board (mean \pm SEM) \\
\hline Control & 10 & $36.40 \pm 3.26$ \\
Standard & 1 & $39.80 \pm 2.22$ \\
n-HSF & 200 & $36.40 \pm 3.26$ \\
& 400 & $64.20 \pm 1.77^{* * *}$ \\
CSF & 200 & $72.20 \pm 2.71^{* * *}$ \\
& 400 & $71.60 \pm 2.20^{* * *}$ \\
EASF & 200 & $81.20 \pm 2.60^{* * *}$ \\
& 400 & $46.00 \pm 1.41$ \\
MCE & 200 & $57.00 \pm 1.22^{* *}$ \\
& 400 & $63.60 \pm 1.72^{* * *}$ \\
ASF & 200 & $75.20 \pm 1.71^{* *}$ \\
& 400 & $45.00 \pm 3.21$ \\
\hline
\end{tabular}

Each value represents the mean $\pm \operatorname{SEM}(n=5)$

MCE methanol crude extract, EASF ethyl acetate soluble fraction, $n$-HSF $\mathrm{n}$-hexane soluble fraction, CSF chloroform soluble fraction, ASF aqueous soluble fraction, SEM standard error mean

The inter group significance was analysed by one-way ANOVA using Dunnet's t-test. $P<0.05^{*}, P<0.01^{* *}$ and $P<0.001^{* * *}$ indicates weak, moderate and high significance respectively 
Table 6 Effects of different fractions of MCE of B. nigra flowers on in vitro clot lysis

\begin{tabular}{lll}
\hline Sample & Dose $(\mathbf{m g} / \mathbf{m l})$ & Percentage of clot lysis (mean \pm SEM) \\
\hline Blank & & $6 \pm 1.09$ \\
Streptokinase & & $46.39 \pm 2.92$ \\
n-HSF & 5 & $18.92 \pm 2.94^{* *}$ \\
& 10 & $22.78 \pm 2.05^{* * *}$ \\
CSF & 5 & $30.77 \pm 4.09$ \\
& 10 & $36.89 \pm 1.94^{* * *}$ \\
ASF & 5 & $10.92 \pm 2.32^{* *}$ \\
& 10 & $17.32 \pm 2.48^{*}$ \\
MCE & 5 & $9.59 \pm 1.82^{* * *}$ \\
& 10 & $21.59 \pm 1.52^{* * *}$ \\
\hline
\end{tabular}

Each value represents the mean $\pm \operatorname{SEM}(n=5)$

MCE methanol crude extract, EASF ethyl acetate soluble fraction, $n-H S F$ nhexane soluble fraction, CSF chloroform soluble fraction, SEM standard error mean

The inter group significance was analysed by one-way ANOVA using Dunnet's t-test. $P<0.05^{*}, P<0.01^{* *}$ and $P<0.001^{* * *}$ indicates weak, moderate and high significance respectively

$100 \mu \mathrm{g} / \mathrm{ml}$ [14]. From the $\mathrm{LC}_{50}$ values, we conclude that the CSF $(1.563 \mu \mathrm{g} / \mathrm{ml})$ contains more potent cytotoxic compounds compared to the other fractions. On the other hand, the ASF $(10 \mu \mathrm{g} / \mathrm{ml})$ showed relatively less toxicity. There was no mortality in the negative control groups indicating the test was a valid one. Various studies revealed that plant extract shows cytotoxicity due to the presence of phytochemical compounds like flavanoids, glycosides, tannins, saponins and alkaloids which have been observed in this study [36, 37]. Saponins exert their cytotoxic activity through the apoptosis pathway which is a process of programme cell death [38]. Another study reported that saponins work by stopping cellular mutation that leads to cancer [30]. It is believed that tannins exert cytotoxicity by blocking induction of enzyme needed for cancer cell line growth [36]. Again, flavonoids exhibit cytotoxicity through increasing the production of intracellular ROS level [39] whereas alkaloids act by inhibiting the proliferation of a number of tumour cells [40]. These phytochemicals have been noticed in our study. Therefore, we can claim that the positive response obtained in our investigation suggests that the plants may contain cytotoxic agents which could be developed for medicinal use.

In anthelminthic activity test, all the fraction of extract provoke not only paralysis but also death of the earthworms in dose-dependent manner. From the study, we observed that the paralysis and death time of earthworm were inversely proportional to the extract concentrations. Among the fractions, n-HSF showed less paralysis $(13.20 \pm .58)$ and death $(22.40 \pm 1.36)$ time which was potential when compared with standard $(35.40 \pm .51$ and $73.40 \pm 1.21$, respectively). Several studies claimed that tannins, flavonoids, alkaloids and phenolic compounds are accountable for anthelmintic activity $[41,42]$. Tannins can bind to free proteins in the gastrointestinal tract of host animal or glycoprotein on the cuticle of the parasite and thereby cause deaths [41, 42]. Tannins may exhibit their activity by intervening with energy production of worms through uncoupling oxidative phosphorylation that leads to death [42]. On the other hand, alkaloids induce paralysis of worms by acting on its central nervous system [42]. Our phytochemical screening exhibited the presence of alkaloids, flavonoids, tannins and phenolic compounds. Hence, we can consider the flower of B. nigra as an alternative source of anthelmintic drugs.

In case of thrombolytic test, it can be demonstrated that our findings may have significant implications in cardiovascular health. A widely used thrombolytic agent streptokinase acts by converting additional plasminogen to plasmin. But this agent has several adverse effects which encouraged the researcher to discover alternative agent [43]. Therefore, we tried to find out whether the plant possesses clot lysis property or not. The comparative study between positive and negative control clearly showed that clot lysis did not occur when water was added to the clot. On the other hand, addition of different fractions of extract revealed a significant clot lysis. Among the different fractions, CSF showed highest clot lysis $(30.77 \pm 4.09)$. Several studies reveal that tannins, alkaloids and saponins are responsible for clot lysis activity [44, 45]. It is assumed that these phytochemicals exert their activity by disrupting the fibrinogen and fibrin in a clot that ultimately leads to fibrinolysis $[44,45]$. As phytochemical analysis revealed that the crude extract contains tannins, alkaloids and saponins, it may predict that these phytochemicals may be responsible for its clot lysis activity.

Elevated plus maze and hole board were used to estimate the psychomotor performance and emotional aspects of mice. Moreover, we know that anxiolytic agents raise the time spent and a number of entries in open arms of the EPM [10, 46]. The result of the study showed that different fractions of plant extract at both dose $200 \mathrm{mg} / \mathrm{kg}$ and $400 \mathrm{mg} / \mathrm{kg}$ treated into mice showed significant increases in time spent and the number of entries in open arms in comparison to the control group. On the other hand, both the time spent and number of entry decreased in close arms in comparison to the control group. Again, in case of hole board test, the head dipping of animals is inversely proportional to their anxiety state in the moderately aversive environment [10, 47]. Therefore, an increasing number of head dipping of mice into the holes of board indicate declined anxiety state. Previous investigations suggested that alkaloids, flavonoids and terpenoids are accountable for anxiolytic activity which was observed in our study [10]. Flavonoids induce anxiolytic effect by 
opening activated chloride channel to increase permeability of neuronal membrane chloride ions that results in GABA's inhibitory effect [10]. Again, alkaloids such as montanine initiate anxiolytic activity by reducing the locomotor activity [48]. Thus, we may conclude that the methanol extract of $B$. nigra flowers and its fractions have satisfactory anxiolytic potential.

From the light of above study, it can easily be mentioned that the methanol extract and its different fractions of B. nigra flowers are a vital source of therapeutic agents having the thrombolytic, anthelmintic, anxiolytic and cytotoxic potentiality.

\section{Conclusion}

On the basis of the findings of the present study, it can be determined that methanol extract of Brassica nigra flowers possesses different types of pharmacological activities in varying concentration and fractions. At the end, it can be concluded that the experimental evidence obtained in the laboratory test model could provide a rationale for the traditional use of this plant as an anthelmintic, thrombolytic, anti-tumour and anxiolytic agent. Future scope involves the isolation of phyto-constituents that are responsible for anthelmintic, thrombolytic, cytotoxic and anxiolytic activity and the study of its pharmacological actions.

\section{Abbreviations \\ TPA: Tissue plasminogen activator; BNH: Bangladesh National Herbarium; VS: Vincristine sulphate; MCE: Methanol crude extract; EASF: Ethyl acetate soluble fraction; n-HSF: n-Hexane soluble fraction; CSF: Chloroform soluble fraction; ASF: Aqueous soluble fraction; $\mathrm{LC}_{50}$ : Lethal concentration 50; ROS: Reactive oxygen species; SEM: Standard error mean; \\ DNA: Deoxyribonucleic acid; GABA: Gamma-amino-butyric acid; \\ DMSO: Dimethyl sulfoxide; EPM: Elevated plus maze}

\section{Acknowledgements}

The authors would like to express their heartiest gratefulness to Square Pharmaceutical Ltd, Bangladesh. The authors are also thankful to all the teachers and staffs of the Department of Pharmacy, Noakhali Science \& Technology University, for their cordial co-operation to carry out the research work.

\section{Source of the plant}

The plant was collected from the local area of Noakhali.

\section{Authors' contributions}

We declare that this study was conducted by the authors named in this article: MSU, MF and MSM designed the study. MSH, MGU and SAS carried out the laboratory work, analysed the data and wrote the manuscript. MSU and MGU helped to supervise the work and collaborated in the data analysis while MSM revised and corrected the manuscript. All authors read and approved the final manuscript.

\section{Funding}

No funding was received.

\section{Ethics approval and consent to participate}

The ethical approval for conducting the study was taken from the ethical approval committee of Noakhali Science \& Technology University. The reference number is 03/2019.

\section{Consent for publication}

Not applicable.

\section{Competing interests}

The authors declare that they have no competing interests.

\section{Author details}

'Department of Pharmacy, Noakhali Science \& Technology University, Noakhali 3814, Bangladesh. ${ }^{2}$ Department of Pharmacy, University of Chittagong, Chittagong 4331, Bangladesh. ${ }^{3}$ Department of Pharmacy, Atish Dipankar University of Science and Technology, Uttara, Dhaka 1230, Bangladesh.

Received: 14 January 2020 Accepted: 31 August 2020

Published online: 22 October 2020

\section{References}

1. Biswas K, Chattopadhyay I, Banerjee RK, Bandyopadhyay U (2002) Biological activities and medicinal properties of neem (Azadirachta indica). Currnt Sci 82(11):1336-1345

2. Hossain MS, Hossain MS, Amin MT, Millat MS (2016) In vitro thrombolytic potentials of methanolic extract of Vigna unguiculata Linn (seed). J Pharmacogn Phytochem 5(3):129-131

3. Hussain MS, Ibrahim M, Hasan MM, Aziz MT, Suchi SA, Uddin MG (2018) An in vivo study of the pharmacological activities of a methanolic acetate fraction of Pistia stratiotes L.: an ethno-medicinal plant used in Bangladesh. Animal Model Exp Med 1(3):221-227

4. Chawla R, Thakur P, Chowdhry A, Jaiswal S, Sharma A, Goel R, Sharma J, Priyadarshi SS, Kumar V, Sharma RK, Arora R (2013) Evidence based herbal drug standardization approach in coping with challenges of holistic management of diabetes: a dreadful lifestyle disorder of 21 st century. J Diabetes Metab Disord 12(1):35

5. Sen N, Bulbul L, Hussain F, Amin MT (2016) Assessment of thrombolytic, membrane stabilizing potential and total phenolic content of Typha elephantina Roxb. J Med Plants Res 38:669-675

6. Moghal MMR, Millat MS, Hussain MS, Islam MR (2016) Thrombolytic and membrane stabilizing activities of Launaea sarmentosa. Int J Pharmacog 3(8):354-358

7. Netto SM, Warela RWB, Fechine MF, Queiroga MN, Quintans-Junior LJ (2009) Anxiolytic-like effect of Rauvolfia ligustrina Willd. Ex Roem. \& Schult, Apocynaceae, in the elevated plus-maze and hole-board tests. Braz J Pharm 19(4):888-892

8. Hellion-Ibarrola MC, Ibarrola DA, Montalbetti Y, Kennedy ML, Heinichen O, Campuzano M, Tortoriello J, Fernandez S, Wasowski C, Marder M, De-Lima TCM (2006) The anxiolytic-like effects of Aloysia polystachya (Griseb.) Moldenke (Verbenaceae) in mice. J Ethnopharmacol 105(3):400-408

9. Mishra SK, Sing PN, Dubey SD Evaluation of CNS depressant activity of Capparis zeylenica Linn.root. Res J Med Plants 5(6):738-746 92011

10. Islam A, Hussain MS, Sen N, Abedin F, Millat MS, Islam MS, Das A, Kar A, Hossain MM (2017) Investigation of in vitro thrombolytic and antihelminthic activity and in MARK vivo anxiolytic and antidepressant potentiality with phytochemical nature of methanolic extract of Leucas lavandulifolia. Sustain Chem Pharm 6:61-67

11. Islam T, Das A, Shill KB, Karmakar P, Islam S, Sattar MM (2015) Evaluation of membrane stabilizing, anthelmintic, antioxidant activity with phytochemical screening of methanolic extract of Neolamarckia cadamba fruits. J Med Plants Res 9(5):151-158

12. Akhtar MS, lqbal Z, Khan MN, Lateef M (2000) Anthelmintic activity of medicinal plants with particular reference to their use in animals in the Indo-Pakistan subcontinent. Small Rumin. Res 38(2):99-107

13. de Mesquita ML, de Paulab JE, Pessoac C, de Moraesc MO, Costa-Lotufoc LV, Grougnet R, Michel S, Tillequin F, Espindola LS (2016) Cytotoxic activity of Brazilian Cerrado plants used in traditional medicine against cancer cell lines. J Ethnopharmacol 123(3):439-445

14. Hossain M, Hussain MS, Moin-UI-Islam RMA, Millat MS, Sweety MN (2016) Exploration of In-vitro antimicrobial and cytotoxic potentials of crude 
methanolic extracts of Quisqualis indica (stem bark): an ethno medicinal plant. Int J Biological Res 4(2):280-287

15. Balunas MJ, Kinghorn AD (2005) Drug discovery from medicinal plants. Life Sci 78(5):431-441

16. Uddin MS, Huda MN, Mosharraf S, Millat MS (2019) Assessment of antidiarrheal action of the methanolic extract of Brassica nigra flower in Swiss albino mice. Discovery Phytomedicine 6(2):56-60

17. Lankau RA, Wheeler E, Bennett AE, Strauss SY (2011) Plant-soil feedbacks contribute to an intransitive competitive network that promotes both genetic and species diversity. J Ecol 99:176-185

18. Finley JW, Sigrid-Keck A, Robbins RJ, Hintze KJ (2005) Selenium enrichment of broccoli: interactions between selenium and secondary plant compounds. J Nutr 135(5):1236-1238

19. Kiasalari Z, Khalili M, Roghani M, Sadeghian A (2012) Antiepileptic and antioxidant effect of Brassica nigra on pentylenetetrazol-induced kindling in mice. Iran J Pharm Sci 11(4):1209-1217

20. Ramani SG, Bajracharya R (2016) Antiepileptic and anxiolytic activity of ethanolic extract of Brassica nigra L. Koch seeds on Wistar albino rats. Eur J Pharm Med Res 3(4):394-402

21. Ahmed SA, Kamel EM (2013) Chemical constituents, cytotoxic and antibacterial activities of the aerial parts of Brassica nigra. Int J Bioassays 2: $1134-1138$

22. Katz E, Nisani S, Chamovitz DA (2018) Indole-3-carbinol: a plant hormone combatting cancer. F1000Research 7

23. Lee YH, Choo C, Waisundara VY (2015) Determination of the total antioxidant capacity and quantification of phenolic compounds of different solvent extracts of black mustard seeds (Brassica nigra). Int J Food Prop 18(11):2500-2507

24. Farnham MW, Kopsell DA (2009) Importance of genotype on carotenoid and chlorophyll levels in broccoli heads. HortScience 44(5):1248-1253

25. Chen U, Hussain MS, Mazumder T, Uddin SMN, Banik S (2019) Neuropharmacological evaluation of methanolic extract of Costus speciosus Linn. rhizome in Swiss albino mice. Asian Pac J Trop Biomed 9(5):217-221

26. Naznin S, Ferdous M, Uddin MS, Yeasmin F, Daulla AS, Anwarul M (2019) A study on phytochemical investigation and evaluation of antioxidant potentials of Globba marantina (Leaves). J Med Plant Res 7(6):147-153

27. Millat MS, Amin MN, Uddin MS (2019) Phytochemical screening and antimicrobial potential analysis of methanolic extracts of ten days mature Triticum aestivum Linn. (Whole Plants). Discovery Phytomedicine 6(1):16-19

28. Rahman MM, Devi R, Megha PU (2018) Phytochemical screening and invitro antimicrobial activity of Pogostemon quadrifolius (benth) of Lamiaceae. Int J Pharmaceutical Sci Res 9(6):2438-2445

29. Shivkar YM, Kumar VL (2003) Anthelmintic activity of latex of Calotropis procera. Pharm Biol 41(4):263-265

30. Prasad S, Kashyap RS, Deopujari JY, Purohit HJ, Taori GM, Daginawala HF (2006) Development of an in vitro model to study clot lysis activity of thrombolytic drugs. Thrombosis J 4(14):1-4

31. Adeyemi OO, Yemitan OK, Taiwo AE (2006) Neurosedative and musclerelaxant activities of ethyl acetate extract of Baphia nitida AFZEL. J Ethnopharmacol 106(3):312-316

32. Dhara AK, Pal S, Nag Chaudhuri AK (2002) Psychopharmacological studies on Tragia involucrata root extract. Phytother Res 16(4):326-330

33. Gandhare B, Kavimani S, Rajkapoor B (2013) Acute and subacute toxicity study of methanolic extract of Ceiba pentandra (Linn.) Gaertn. on rats. J Sci Res 5(2):315-324

34. Ali MR, Kuri S, Das A, Islam MA (2013) Preliminary phytochemical screening and in vitro thrombolytic potential of the methanolic extract of Enhydra fluctuans Lour (leaves). Int Jour of Pharmamedix India 1:270-280

35. Leta GC, Mourao PA, Tovar AM (2002) Human venous and arterial glycosaminoglycans have similar affinity for plasma low-density lipoproteins. Biochim Biophys Act 1586(3):243-253

36. Musa AA (2012) Cytotoxicity activity and phytochemical screening of Cochlospermum tinctorium Perr Ex A. Rich Rhizome. J Appl Pharm Sci 2(7): 155-159

37. Olaleye MT (2007) Cytotoxicity and antibacterial activity of methanolic extract of Hibiscus sabdariffa. J Med Plants Res 1:9-13

38. Alam F, us Saqib QN, Waheed A (2017) Cytotoxic activity of extracts and crude saponins from Zanthoxylum armatum DC. against human breast (MCF-7, MDA-MB-468) and colorectal (Caco-2) cancer cell lines. BMC Complement Altern Med 17(1):368
39. Matsuo M, Sasaki N, Saga K, Kaneko T (2005) Cytotoxicity of flavonoids toward cultured normal human cells. Biol Pharm Bull 28(2):253-259

40. Lamchouri F, Zemzami M, Jossang A, Abdellatif A, Israili ZH, Lyoussi B (2013) Cytotoxicity of alkaloids isolated from Peganum harmala seeds. Pak Pharm Sci 26(4):699-706

41. Athanasiadou S, Kyriazakis I, Jackson F, Coop RL (2001) Direct anthelmintic effects of condensed tannins towards different gastrointestinal nematodes of sheep: in vitro and in vivo studies. Vet Parasitol 99:205-219

42. Aziz A, Raju GS, Das A, Ahmed J, Moghal MM (2014) Evaluation of in vitro anthelmintic activity, total phenolic content and cytotoxic activity of Crinum latifolium L.(Family: Amaryllidaceae). Adv pharm bull 4(1):15-19

43. Bhowmick R, Sarwar MH, Dewan SMR, Das A, Das B, Uddin MMN, Islam MS (2014) In vivo analgesic, antipyretic, and anti-inflammatory potential in Swiss albino mice and in vitro thrombolytic activity of hydroalcoholic extract from Litsea glutinosa leaves. Biol Res 47(56):1-8

44. Ramjan A, Hossain M, Runa JF, Md H, Mahmodul I (2014) Evaluation of thrombolytic potential of three medicinal plants available in Bangladesh, as a potent source of thrombolytic compounds. Avicenna J Phytomed 4(6): 430-436

45. Bhowmick R, Sarwar MS, RahmanDewan SM, Das A, Das B, NasirUddin MM, Islam MS, Islam MS (2014) In vivo analgesic, antipyretic, and antiinflammatory potential in Swiss albino mice and in vitro thrombolytic activity of hydroalcoholic extract from Litsea glutinosa leaves. Biol Res 47(1):56

46. Pellow S, File SE (1986) Anxiolytic and anxiogenic drug effects on exploratory activity in an elevated plus-maze: a novel test of anxiety in the rat. Pharmacol Biochem Behav 24(3):525-529

47. Bilkei-Gorzo A, Gyertyan I (1996) Some doubts about the basic concept of the hole-board test. Neurobiology 4(4):405-415

48. da Silva AF, de Andrade JP, Bevilaqua LR, de Souza MM, Izquierdo I, Henriques AT, Zuanazzi JÂ (2006) Anxiolytic-, antidepressant-and anticonvulsant-like effects of the alkaloid montanine isolated from Hippeastrum vittatum. Pharmacol Biochem Behav 85(1):148-154

\section{Publisher's Note}

Springer Nature remains neutral with regard to jurisdictional claims in published maps and institutional affiliations.

\section{Submit your manuscript to a SpringerOpen ${ }^{\circ}$ journal and benefit from:}

- Convenient online submission

- Rigorous peer review

- Open access: articles freely available online

- High visibility within the field

- Retaining the copyright to your article

Submit your next manuscript at $\boldsymbol{\nabla}$ springeropen.com 